\title{
ADOLESCÊNCIA, ATO INFRACIONAL E MEDIDAS SOCIOEDUCATIVAS À LUZ DA PSICANÁLISE: UM ESTUDO DE REVISÃO SISTEMÁTICA DE LITERATURA
}

\author{
ADOLESCENCE, INFRACTION ACT AND EDUCATIONAL MEASURES IN THE LIGHT OF \\ PSYCHOANALYSIS: A STUDY OF SYSTEMATIC LITERATURE REVIEW
}

ADOLESCENCIA, DELITOS MENORES Y MEDIDAS EDUCATIVAS A LA LUZ DEL PSICOANÁLISIS: UN ESTUDIO DE REVISIÓN SISTEMÁTICA DE LITERATURA

\author{
Sônia Wan Der Maas Rodrigues* \\ Leônia Cavalcante Teixeira**
}

\begin{abstract}
RESUMO
Este estudo buscou compreender questões relacionadas à adolescência, ato infracional e medidas socioeducativas, tendo a psicanálise como orientação teórica. Para isso, realizou-se pesquisa em revistas indexadas nas bases de dados Pepsic, Scielo, Redalyc, Doaj e Lilacs, publicadas nacionalmente, no período de 2009 a 2014. Selecionou-se, inicialmente, 310 artigos que contivessem como descritores: adolescência, medidas socioeducativas, ato infracional e psicanálise. Destes, foram escolhidos 30 artigos após os critérios de exclusão. Os resultados categorizados pelas ênfases mostraram que o fenômeno dos adolescentes envolvidos em atos infracionais é complexo devido à sua multicausalidade e exige aprofundamento sobre adolescência, relações familiares, nuances do mundo contemporâneo e o acesso aos bens e ao consumo, também a saída do adolescente pelo ato infracional. A clínica psicanalítica, ao oferecer ao sujeito um espaço de escuta, colabora para a construção de novas formas de existência que não sejam pela via da transgressão à ordem social.
\end{abstract}

Palavras-chave: Psicanálise. Adolescência. Ato infracional. Revisão sistemática de literatura.

\footnotetext{
Texto recebido em 26 de outubro de 2016 e aprovado para publicação em 27 de abril de 2018 .

*Doutoranda e mestra em Psicologia pela Universidade de Fortaleza (Unifor), membro do Laboratório de Estudos sobre Psicanálise Cultura e Subjetividade (Laepcus), psicóloga e psicanalista. Endereço: Rua Júnior Rocha, 245 - Parque Manibura, Fortaleza-CE, Brasil. CEP: 60821-585.E-mail: soniawandermaas@gmail.com. Autora do artigo.

**Pós-doutorado em Psicologia pela Universidade Aberta de Portugal, doutora em Saúde Coletiva (IMS/UERJ), mestra em Educação pela Universidade Federal do Ceará, professora titular no Programa de Pós-Graduação em Psicologia da Unifor, bolsista produtividade CNPq, membro do GT da ANPEPP "Psicanálise, Política e Clínica”, membro do Laepcus, psicóloga e psicanalista. Endereço: Rua Henriqueta Galeno, 1080-2301 - Dionísio Torres, Fortaleza-CE, Brasil. CEP: 60135-420. E-mail: leonia.ct@gmail.com. Orientadora.
} 


\section{ABSTRACT}

This study aimed to understand the issues related to adolescence, infraction acts and educational measures, using psychoanalysis as theoretical orientation. The research was carried out in journals from the database of Pepsics, Scielo, Redalyc, Doaj and Lilacs published from 2009 to 2014. Three hundred and ten articles (310) displaying the themes: adolescence, social and educational measures, criminal offense and psychoanalysis were selected. Thirty (30) of them were selected after applying exclusion criteria. The qualified results showed that the phenomenon of teenagers involved in illegal acts is complex mainly because of its multiple causes and demands deeper studies of family relations, the contemporary world nuances, the access to the consumption of goods and also the adolescent's way out through the infraction act. The psychoanalytic clinic contributes to the construction of new forms of existence other than the path of transgression of the social order by offering a space to be heard.

Keywords: Psychoanalysis. Adolescence. Infraction act. Systematic literature review.

\section{RESUMEN}

Este estudio buscó comprender los temas relacionados con la adolescencia, los delitos y las medidas educativas, utilizando el psicoanálisis como orientación teórica. Para eso se llevó a cabo la investigación en revistas indexadas en las bases de datos Scielo, Pepsic, Redalyc, Doaj y Lilacs publicados a nivel nacional, en el período 2009-2014. Fueron seleccionados inicialmente 310 artículos que contenían los temas: adolescencia, medidas educativas, delitos y psicoanálisis. De estos, en seguida, fueron seleccionados 30 artículos por el criterio de exclusión. Los resultados clasificados mostraron que el fenómeno de adolescentes involucrados en actos ilegales es complejo debido a sus múltiples causas y requiere la profundización de la adolescencia, de las relaciones familiares, de las peculiaridades del mundo contemporáneo, y el acceso a los bienes y al consumo de los adolescentes también conducen al acto infraccional. La clínica psicoanalítica, para ofrecer al sujeto un espacio de escucha, contribuye a la construcción de nuevas formas de existencia que no sea a través de la transgresión del orden social.

Palabras clave: Psicoanálisis. Adolescencia. Delitos menores. Revisión sistemática de literatura. 


\section{INTRODUÇÃO}

população adolescente no Brasil, segundo dados estatísticos (Brasil, 2015) $A$ é de 26.154.356. Desse número, 15.221 cumpriam medida de internação; 1 5.573, de internação provisória; e 2.272, de semiliberdade. De acordo com o Sistema Nacional de Atendimento Socioeducativo (Sinase) (Brasil, 2013), em 2011, somavam 88.075 adolescentes que cumpriam medidas socioeducativas em meio aberto (liberdade assistida e prestação de serviço à comunidade) por terem cometido atos infracionais. Essa realidade convoca a um estudo teórico e prático, buscando compreendê-la de forma mais abrangente, haja vista que estamos diante de uma situação caótica, delicada e de difícil solução, sobretudo pela violência tão sangrenta.

A violência e suas variadas formas de expressões (aqui retratada pelo ato infracional) e de causas se fizeram presentes na sociedade, em todas as épocas e em qualquer âmbito, e não podem ser reduzidas apenas às questóes financeiras ou de ordem familiar (Ferrari, 2006; Guerra \& Cunha, 2015). Consideram-se as desigualdades sociais, o racismo, a concentração de renda e a dificuldade de acesso aos bens e serviços sociais, sanitários, culturais e a políticas públicas, bem como motivações de ordem psíquica (Marino \& Priszkulnik, 2011; Padovani \& Ristun, 2013).

A relevância desse tema se fundamenta na repercussão de que, cotidianamente, adolescentes e jovens estão, de alguma maneira, envolvidos em casos de violência. No Brasil, cresce, a cada dia, a soma de adolescentes, compreendidos entre 12 e 18 anos, vítimas ou autores de assassinatos, furtos e roubos, cuja grande motivação é o tráfico de drogas e a adesão a facções criminosas ${ }^{1}$, e, por conta disso, para alguns são imputadas as medias socioeducativas (Waiselfisz, 2014).

Esse cenário conduz a população a tomar uma posição, pensar e até legislar uma saída para essa situação. Não é sem motivos que temas como a criminalidade juvenil e a redução da maioridade penal estão presentes diariamente na mídia (como a Proposta de Emenda à Constituição 171/1993), exigindo modificações na legislação, visando ao endurecimento das medidas socioeducativas, já que consideradas como não reabilitadoras, não cumprindo a função de ressocializar (Amaro, 2004; Cardoso, 2014), conforme seu objetivo inicial, preconizado no Estatuto da Criança e do Adolescente (ECA) (Lei no 8.069, 1990).

${ }^{1}$ Dados publicados no relatório da Comissão Interamericana de Direitos Humanos, Violencia, niñez y crimen organizado (Crianças. ., 2016). 
O tema é complexo e exige estudo, pensamento reflexivo e escuta clínica. Está situado nas interfaces entre campos disciplinares como Sociologia, Antropologia, Direito, Psicanálise, Educação, etc. Reconhece-se a multicausalidade e não possibilidade de apreensão do fenômeno por vieses reducionistas e unilaterais, como a família não estruturada de modo convencional como causa de o adolescente cometer infração, lugar onde mora, escola que frequenta, entre outros.

Deverão ser observados aspectos pertinentes à fragilidade social (estrutura e dinâmica familiares, pobreza, falta ou baixa escolaridade, dificuldade de acesso a bens materiais, etc.) e fragilidade psíquica do sujeito que se encontra numa fase de vida que requer maior atenção, a adolescência (Rodrigues \& Teixeira, 2014). Esse momento, entendido como lógico, de acordo com Rassial (1997, 1999), traz vários desafios ao sujeito (Marin, 2009; Mohr \& Valore, 2009; Sena \& Farias, 2010; Ayub \& Macedo, 2011; Santos \& Pratta, 2012). Somandose a isso há os aspectos da Contemporaneidade que atravessam os modos de subjetivação (Salum \& Santiago, 2012; Danziatto, Carvalho, \& Paiva, 2013). Hoje a atenção se volta para o recrutamento de crianças e adolescentes feito pelas facções criminosas, especialmente aos que estão em condições socialmente desfavorecidas, fruto de desassistência do Estado em relação aos direitos humanos básicos dos indivíduos (Organização dos Estados Americanos, 2015).

Diante desse panorama, atentou-se para a importância de construir-se um estudo sistematizado que contemplasse a adolescência, o ato infracional e as medidas socioeducativas com base no aporte psicanalítico, por configurar um dos campos de pesquisa das autoras. Foi escolhida a revisão sistemática de literatura, objetivando coletar os dados e analisá-los, a fim de apresentá-los à comunidade científica, sobre esse tema tão em voga nos dias de hoje, haja vista a escassez de publicações no campo da psicanálise que se utilizam dessa metodologia de estudo, que se coloca como fonte de rigor científico, análise crítica e síntese dos dados selecionados. 


\section{METODOLOGIA}

Escolheu-se trabalhar com essa metodologia pelos seguintes motivos:

a) poucos artigos são publicados com essa metodologia no campo da psicanálise;

b) constitui-se um modo de se fazer pesquisa que se pretende otimizar o potencial de busca por determinado tema;

c) uma maior organização para apresentação dos artigos estudados, exigindo um trabalho reflexivo e crítico por parte do autor (Fernandez-Ríos \& Buela-Casal, 2009).

A metodologia que sustentou a execução deste trabalho foi a revisão sistemática de literatura e os seguintes procedimentos, buscando nortear e sistematizá-lo em oito etapas (Costa \& Zolowski, 2014):

a) delimitação da questão norteadora;

b) escolha das bases de dados;

c) definição dos descritores para a busca;

d) busca e armazenamento dos resultados;

e) seleção dos artigos pelo resumo, de acordo com os critérios de inclusão e exclusão;

f) obtenção dos dados dos artigos selecionados;

g) avaliação dos artigos; e

h) síntese e interpretação dos dados.

A questão norteadora deste estudo foi apresentar como a psicanálise tem problematizado e apresentado a relação entre adolescência, ato infracional e medidas socioeducativas. A pesquisa foi realizada nos meses de outubro a 
dezembro de 2014, mediante busca de artigos publicados eletronicamente em revistas indexadas nas bases de dados Psi, Pepsic, Scielo e Lilacs; a partir dos descritores "adolescência", "medidas socioeducativas", "ato infracional" e "psicanálise".

Contabilizaram-se 310 artigos publicados em periódicos que contivessem como descritores os binômios "adolescência e psicanálise", "adolescente e psicanálise", "medidas socioeducativas e psicanálise", "ato infracional e psicanálise". Posteriormente, foi feita a leitura dos resumos e palavras-chave desses artigos, selecionando aqueles que contemplassem, em seus resumos e descritores, estudos sobre a adolescência relacionada ao ato infracional e as medidas socioeducativas, e outras discussões que se relacionam a esse tema, com base nos constructos teóricos da psicanálise, somando-se um total de 30 artigos. Foram excluídos 94 trabalhos repetidos.

Os critérios de escolha contemplaram:

a) veículo e modalidade de comunicação: foram escolhidos apenas artigos empíricos, teóricos e de revisão sistemática da literatura, publicados em revistas indexadas por levar em consideração a busca de maior rigor quanto à avaliação exigida para uma publicação científica;

b) idioma de publicação: optou-se por trabalhar apenas com artigos publicados em português e nacionalmente;

c) ano de publicação: a pesquisa compreendeu o período de 2009 a 2014, privilegiando as produções atuais e que exprimissem discussões que já considerassem as realidades sociais e institucionais, inclusive em relação aos desdobramentos das leis e comprometimento da pesquisa acadêmica com problemáticas sociais e de política pública. O que tem a ver com a relação, cada vez mais trabalhada, entre psicanálise, universidade e políticas públicas.

Posteriormente, foi feita a aplicação dos critérios de exclusão: artigos duplicados e que não se encaixassem nos critérios de inclusão, como ano da publicação, publicações nacionais, teses, livros, dissertações, resenhas, conferências e outras modalidades de comunicação e de publicação; e ainda, temas distanciados da temática investigada, por exemplo, artigos de outras abordagens teóricas. 
Selecionaram-se, então, 30 artigos que compuseram o corpus deste estudo, para um aprofundamento maior e mais detalhado. Concomitantemente ao estudo dos artigos, foi-se compilando as ideias-chave, agrupando-as em quatro categorias presentes que serão trabalhadas neste artigo: as relações familiares; sobre o adolescer; as medidas socioeducativas e o ato infracional; e a clínica psicanalítica com adolescentes que respondem a medidas socioeducativas.

\section{RESULTADOS E DISCUSSÃO}

A primeira categoria final a que se chegou, a partir dos resultados, foi as "relaçôes familiares", trazendo importantes reflexōes sobre o lugar primordial que estas ocupam na constituição psíquica do sujeito, como eixo de referências simbólicas e como efetivação da castração.

As novas configurações familiares, incluindo casais separados, segundas uniōes, mães que são arrimo de famílias, pais envolvidos no mundo do crime, filhos de produção independente, etc. Esses fatores deixam marcas, uma vez que o pai não é mais o guardião de sua função como outrora. $\mathrm{O}$ que se constata é certa volatilidade da figura paterna (Xavier, Ferreira, \& Paravidini, 2011), o que, a princípio, não se pode colocar com causa de qualquer queixa, configura-se apenas um dado da realidade.

Também são encontradas as famílias extensas. Por exemplo, uma avó que more com seus filhos e netos, todos juntos, dividindo o mesmo espaço. Avó que cuida dos netos e sustenta os filhos. Há uma tendência de fraternização dos vínculos e as figuras de referência bem diluídas, não é raro encontrar situações em que os pais se colocam em posição de equidade com os filhos. Há certa pulverização das referências simbólicas e horizontalização das relações sociais. Falta, portanto, a figura do Outro para que o sujeito se identifique, projete-se na ordem de uma cultura regida por leis e interditos. Em muitos casos, pode-se constatar, além do declínio da função paterna, o declínio da função materna. Falta investimento libidinal da mãe para com seus filhos, pois, como se observa, muitas dessas crianças estão inscritas precariamente no desejo da mãe (Xavier, Ferreira, \& Paravidini, 2011).

O conceito de "nome do pai", caro à psicanálise, é colocado como o que, de fato, localiza o sujeito na lógica da castração. À pessoa que exerça a função materna é exigido que apresente a função paterna, por meio da linguagem, permitindo a quebra da relação dual entre mãe e bebê (Xavier, Ferreira, \& Paravidini, 2011; Marino \& Priszkulnik, 2011; Danziatto, Carvalho, \& Paiva, 
2013; Silva \& Araújo, 2013), que, como se sabe, não se reduz à mãe ou pai biológicos, mas remete àqueles que exercem tais funçôes.

A função materna existe quando o agente materno, mãe biológica ou não, acolhe a criança em seu desamparo original e lhe apresenta o mundo simbólico. Ressalta-se que esse ser também inscrito no registro da falta, nomeado como Outro primordial, é o responsável por inserir a criança no mundo simbólico (Xavier, Ferreira, \& Paravidini, 2011).

Sena \& Farias (2010) fazem uma distinção quanto à figura do pai, com base nos ensinos de Lacan. Duas imagens estão relacionadas, mas não poderão ser confundidas, que são o pai normativo e o pai normal. O primeiro diz de uma estrutura; o segundo, de uma posição pessoa. A função do pai, portanto, é ocupar o seu lugar no Édipo e na proibição do incesto, servindo-se de identificação, fazendo operar a castração e a efetivação da lei.

Logo, o conflito edípico é um vetor estruturante para o sujeito, permitindo a ele novas identificações e construções de fantasias inconscientes, pois todo o processo do desenvolvimento é atravessado por questôes relacionadas ao nascimento, à separação, ao Édipo, à latência, à eleição do objeto e à adolescência (Ayub \& Macedo, 2011; Santos \& Zeitoune, 2011).

Ao longo dos tempos e apesar das diferentes concepções, configurações, crises e mudanças, a família se mantém como uma estrutura fundamental para a formação do indivíduo e da sociedade, oferecendo caminhos para inserção e sobrevivência no social, já que essa instituição, quase sempre, representa um lugar que remete à proteção, ao afeto e à segurança (Santos \& Pratta, 2012), mas há exceções. Nota-se que, em sua maioria, os adolescentes que estão em cumprimento de medida socioeducativa têm relações difíceis e conflituosas com seus pais e, ou, família, vivem nas ruas e poucos estão nas escolas. Não raras vezes, estão longe de oferecerem estrutura, abrigo e proteção.

A segunda categoria final foi "sobre o adolescer". Diferentes são os modos de olhar para essa fase da vida humana. O Estatuto da Criança e do Adolescente (ECA), a Organização Mundial de Saúde (OMS), Instituto Brasileiro de Geografia e Estatística (IBGE), os direitos humanos e abordagens que se pautam pela teoria desenvolvimentista acolhem esse momento como peculiar de desenvolvimento (Santos \& Pratta, 2012). A psicanálise aborda como específico de nova reelaboração edípica, do encontro com um outro sexuado, das transformações corporais e de um trabalho subjetivo que implique o adolescente com aquilo que ele vivencia, com o mal-estar que lhe é constituinte. 
A psicanálise afiança que a adolescência é marcada pelo corte com os ideais narcísicos dos pais. É um "tempo de buscar a si próprio em novas relações, recuperar amores perdidos, fundar-se num corpo que foi amado e que poderá amar, que foi gerado e poderá gerar, entrar para a realidade social, simbólica, com nome próprio" (Marin, 2009, pp. 3-4). Assim, é tomada como momento de ressignificação da identificação, onde espaços de interrogações e incertezas possam ser acolhidas e elaboradas. Trocas sociais são de grande importância, pois o adolescente vai se deparar com as exigências que esta nova fase de vida traz, em que a alienação e a separação do outro se fazem presentes e os objetos externos à configuração familiar não assegurarão afeto incondicional (Ayub \& Macedo, 2011). Logo, "um lugar de passagens, encontros, possibilidades, aberturas e fechamentos" (Sena \& Farias, 2010, p. 120).

É um momento que se caracteriza pela transição da infância à idade adulta, saindo da condição de dependência para uma postura de autonomia pessoal, domínio de si e de individualização, quando concorrerão para a constituição do sujeito (Santos \& Pratta, 2012). Do ponto de vista da Filosofia, ao passo que o adolescente se afasta da vida infantil, distancia-se da heteronomia e vai em direção à autonomia. No primeiro momento, o sujeito está submetido às normas do outro, dos pais, dos adultos. Conforme vai crescendo, deverá conquistar, ainda que lentamente, a autonomia, entendida como suas próprias normas (Rosário, 2010).

Marca esse período de transição, esse não lugar, um intervalo (Guerra, Cunha, Costa, \& Silva 2014), um tempo lógico para cada um (Lacadée, 2012), marcado pelo encontro traumático com o real de seu corpo e com um outro, também sexuado. Dar-se-á a aquisição de uma nova imagem corporal, de maturação biológica e capacidade reprodutiva, uma reapropriação egoica do corpo, podendo ser sentida pelo adolescente como ameaçador. Nesse sentido, a adolescência é tomada como uma posição que convoca a rupturas, mas aponta para a construção de uma singularidade, conforme faz laço social com um grupo. Assim, as crises tão presentes na adolescência objetivam "um efeito no sujeito" (Sena \& Farias, 2010, p. 120) e são tomadas como aquilo que desperta o real da sexualidade (Lacadée, 2012).

Ao adolescente caberá a tarefa de elaboração psíquica do seu mal-estar, no intuito de evitar saídas danosas (Mohr \& Valore, 2009, p. 4), como suicídios (Benhaim, 2011), uso de drogas, rebeldia (Mohr \& Valore, 2009; Santos \& Pratta, 2012), violência escolar (Sena \& Farias, 2010), sintomas ditos contemporâneos expressos no corpo (Salum \& Santiago, 2012) e ato infracional (Marin, 2009; Muller, Barboza, Oliveira, Santos \& Paludo, 2009; Xavier, Ferreira, \& Paravidini, 
2011; Ferreira \& Vescovi, 2014), o que se pode inferir que esses sintomas substituem a palavra, a enunciação.

É bastante comum ouvir pessoas atribuírem crise à adolescência. Nem sempre, elas se dão conta que fazem parte da dimensão humana os sofrimentos, desencontros e mal-estar, pois o pathos está na constituição do sujeito. A crise psíquica que o adolescente vivencia diz de um tempo de subjetivação que é peculiar a cada sujeito, cada um a seu tempo; de certo modo, viver é estar em crise.

A terceira categoria final é intitulada "ato infracional e as medidas socioeducativas", na qual foram compiladas as ideias que os autores abordaram em seus textos.

As orientações do ECA são muito claras no tocante ao adolescente que comete o ato infracional e, por isso, responde por medidas socioeducativas. Pautar-se pelo ECA, portanto, é orientar-se para uma posição que toma o adolescente como um ser em desenvolvimento, conferindo a este a política de proteção integral (Gregoracci \& Onofre, 2013). A adolescência é pensada por faixa etária e não por vieses psicológicos e sociais. Nessa perspectiva, as medidas têm como mote a educação do adolescente e o fortalecimento dos vínculos familiares e comunitários, a reinserção social, readaptação, ajustamento social e, de certa forma, uma reorganização psíquica e social, visando a mudanças em seu estilo de vida (Muller et al., 2009; Silva \& Araújo, 2013; Souza \& Moreira, 2014).

Foi observado por Muller et al. (2009) que, em sua maioria, os atos infracionais mais cometidos são o roubo e o furto para suprir necessidades pessoais, ter acesso aos bens e, ainda, para financiar o uso de drogas, usar determinadas marcas, andar armado e ter mulheres; uma forma fácil de ter dinheiro e não serem vistos como "mulherzinhas" ou medrosos, ou seja, um meio de se colocar no social por uma posição fálica (Zeitoune, 2009).

O adolescente quase sempre está acompanhado no momento do ato. O grupo e as gangues têm uma função. Fazer um grupo é compor um caminho, um ir fazendo, continuar atuando até mesmo pelas identificações e anteparo que um oferece ao outro (Salum, 2011). Somos advertidas por Lacan (1964/2008) que o desejo de analista o torna o objeto da transferência, o que nos permite inferir, a partir de relatos de atendimentos clínicos, que vinculação do adolescente com o grupo está ligado à questão da identificação como mais remota expressão de um laço emocional com outra pessoa, fruto do discurso do mestre, em que a ele é apresentado um modelo a ser seguido, para além das questôes normativas. 
A figura do Juiz (aquele que aplica as medidas) funciona, para alguns adolescentes, a modo de um "pai jurídico". Isso se deve ao fato de que ele representa a lei que organiza a vida em sociedade, ao mesmo tempo em que pune e obriga certas condutas e posturas, oferecendo possibilidade de inserção do sujeito no social e, em alguns casos, como efetivação da lei simbólica (Silva \& Araújo, 2013).

Muller et al. (2009), em pesquisa realizada com adolescentes em privação de liberdade, chamam a atenção para os dados encontrados: $41 \%$ destes tinham 18 anos, e $8 \%$ mais que 18 anos. Isso poderia ser explicado por conta de a privação de liberdade ser aplicada em último recurso. A predominância é de brancos, somando $60 \%$, contrariando as estatísticas que apresentam os negros como maioria. A prevalência da figura materna como chefes de família chega a $34 \%$. E ainda, que, em 78\% dos casos, os adolescentes experienciaram violência doméstica antes de cometeram ato infracional, o que permite indagar se, nesses casos, o ato infracional direcionado ao outro é uma resposta violenta à violência recebida do Outro. E, ainda, que a modalidade de ato cometido soma $66 \%$ de delitos contra o patrimônio (roubo e furto).

As medidas socioeducativas são distintas (advertência, obrigação de reparar o dano, prestação de serviços à comunidade, liberdade assistida, inserção em regime de semiliberdade, internação em estabelecimento educacional), correspondendo à gravidade da infração cometida e às condiçôes do adolescente em cumpri-las, de acordo com o ECA. Não há um motivo único que conduza o adolescente ao ato infracional e nem sempre a relação é de causa e efeito. Retrata questóes relacionadas à escola, à família, à sociedade, ao Estado e à sua constituição subjetiva, aos impactos da globalização e à forma com que os laços sociais foram constituídos (Broide, 2010) na lógica capitalista, o que acarreta novas formas de subjetividade na adolescência (Birman, 2006, apud Ayub \& Macedo, 2011; Capanema \& Vorcaro, 2012). Entende-se aqui que, a cada época, o sujeito vivencia, de modo muito singular, as questôes relacionadas a seu processo de adolescer, da mesma forma que não se pode falar em adolescência como sendo uma fase igual para todos; há, sim, diferentes sujeitos vivendo sua adolescência.

Como apresentado anteriormente, a adolescência é marcada por forças pulsionais e exigências sexuais. Nessa perspectiva, Santos e Zeitoune (2011) afirmam que "O ato infracional não é um ato de rebeldia contra a lei simbólica, é uma atuação que surge como resposta ao real das exigências pulsionais da sexuação na adolescência, revelando o embaraço diante do atributo fálico" (p. 
105). Essa afirmação diz de uma prática clínica específica e pontual, e que não poderá ser utilizada em caráter de generalização.

$\mathrm{O}$ ato infracional cometido pelos adolescentes não se encontra apenas em classes sociais menos favorecidas. Em muitos casos, os adolescentes se encontram desassistidos em alguma dimensão pela família (Silva \& Araújo, 2013; Teixeira, 2014). Em alguns episódios, o ato infracional é resultado da ausência da lei paterna na subjetividade da criança, apresentando-se como um sintoma, como um "pedido de controle de pessoas fortes, amorosas e confiantes" (Sena \& Farias, 2010, p. 128).

Uma diferença foi observada por Ayub e Macedo (2011): a escolha por patologias do ato se dá em decorrência da ausência de recursos psíquicos e não de existência de conflitos psíquicos, corroborando, portanto, questôes relacionadas ao adolescer e o lugar da castração na organização psíquica do sujeito, ao contrário da tese defendida por Santos e Zeitoune (2011), de que as patologias do ato viriam no lugar do sintoma, ou seja, do recalque sexual.

Muitas são a leituras que envolvem o autor do ato infracional. Alguns expressam que o crime é, na verdade, a busca pelo interdito, por aquilo que faz limite, que reivindica punição e um olhar, uma posição subjetiva (Marino \& Priszkulnik, 2011; Ferreira \& Vescovi, 2014), um modo de sintoma que busca um laço com o Outro (Salum \& Santiago, 2012), uma possibilidade de acesso aos bens (Xavier, Ferreira, \& Paravidini, 2011) e garantia de notoriedade (Ferreira \& Vescovi, 2014).

Esses posicionamentos retratam o percurso desses autores, no sentido de apresentar que o ato infracional deverá ser observado no contexto da história de vida do sujeito e não apenas como um ato isolado. $\mathrm{O}$ ato, portanto, diz de uma posição subjetiva do sujeito e não apenas de determinantes sociais.

O pensamento foucaultiano tem contribuído para se pensarem as medidas socioeducativas, como bem articulou Rosário (2010). O controle e a disciplina das mentes produzem certos modos de subjetivação ou práticas de si, mediante as quais o corpo poderá ser formado, corrigido, adaptado. A participação nas atividades que compõem o cumprimento das medidas é ambígua. Os adolescentes, em sua maioria, participam das atividades visando unicamente ao relatório de acompanhamento, visto que estas não trazem sentido para eles. Para a instituição, as atividades têm como função "padronizar o comportamento, visando à docilização” (Rosário, 2010, p. 70). 
O relatório psicossocial é um plano de acompanhamento ao adolescente que responde pela medida socioeducativa e tem como objetivo um maior conhecimento sobre o adolescente e suas condiçōes econômicas e sociais. Mas a quem serve esse relatório? Pois, dependendo da forma como este é feito, resulta na criação de perfis: "o delinquente, a vítima, o agressor, o bandido e outros" (Costa, Penso, Sudbrack, \& Jacobina, 2011, p. 384). Não raras vezes, esses relatórios são construídos com base em uma perspectiva determinista, considerando os atos infracionais como tendências definitivas e naturais, desconsiderando a dimensão transitória da fase adolescente.

Esse relatório deveria ser fruto de outra ferramenta, o plano individual de atendimento (PIA), elaborado por uma equipe multi e, ou, interdisciplinar, destinado ao planejamento, registro e gestão das atividades a serem desenvolvidas pelo adolescente. Por meio do PIA, poderá ser acompanhada a evolução pessoal e social do adolescente, suas potencialidades e dificuldades com as situações adversas (Costa et al., 2011). Deverá ser feito pela equipe técnica, o adolescente e seus pais ou responsáveis, e formaliza o início do cumprimento da medida (Melgaço et al., 2014). Para a implantação das medidas e um bom aproveitamento destas, é necessário que a rede socioassistencial tenha um bom fluxo, permitindo acesso à escola, cultura, profissionalização, saúde (Souza \& Moreira, 2014).

$\mathrm{Na}$ quarta e última categoria final deste estudo, intitulada "clínica psicanalítica com adolescentes em medidas socioeducativas", buscou-se recolher as indicações e reflexôes acerca da escuta ao adolescente e sua relação com o ato infracional e as medidas socioeducativas.

A clínica psicanalítica nas instituições tem uma lógica de ser que difere da clínica psicanalítica em consultórios privados. $\mathrm{Na}$ primeira, a inconstância nas sessões se deve a outras, tais como instabilidade da equipe, demoras para organização de ambiente, de contratos para cumprimento da medida, às vezes, falta de transporte para outros equipamentos da rede socioassistencial; são atravessamentos que precisam ser levados em consideração (Altoé \& Silva, 2013). Enquanto que, na segunda, esse aspecto é tomado em outras dimensões, inclusive transferenciais. Já o tempo de permanência do sujeito no acompanhamento feito na instituição é o tempo da medida; no consultório, é o tempo do sujeito, o que não impossibilita um trabalho coeso e eficiente.

A clínica institucional com adolescentes em conflito com a lei deverá contemplar dois pilares: a dimensão socioeducativa, que deverá possibilitar espaços para viver incertezas, amores, dúvidas, estranhamentos, situações nas quais se podem descobrir e introjetar as regras da vivência social; a dimensão terapêutica deverá ser o espaço no qual o sujeito possa se questionar, construir 
novos sentidos para a sua vida (Marin, 2009). Essas dimensões bem articuladas poderão ajudar o sujeito a construir formas mais saudáveis para sua vida e projetos futuros, diferentes daquelas por ele utilizadas até então.

O que orienta a escuta clínica, seja ela nas instituições ou não, é a regra fundamental da psicanálise, a associação livre. É o que permite ao sujeito "sair de seu discurso impessoal para se tornar sujeito de seu discurso" (Altoé \& Silva, 2013, p. 136). Em termos jurídicos, cumprir as medidas socioeducativas é responder pelo ato. Para a psicanálise, é mais que isso. É necessário que o sujeito se interrogue sobre seu ato e os efeitos que ele traz para a sua vida, num processo de responsabilização subjetiva, respondendo por seu ato diante de seus semelhantes com nome próprio (Souza \& Moreira, 2014; Guerra et al., 2014; Teixeira, 2014). Diferentemente de outras abordagens, a psicanálise orienta seu trabalho pelas diferenças, abrindo mão de generalizações e receitas prontas, em uma posição de escuta que privilegia o que há de particular em cada sujeito e sua história, seus pontos de captura e de seus desejos (Vilhena, Zamora, \& Rosa, 2011).

Colocar-se como quem nada sabe, para que, a partir daí, o sujeito e suas manifestaçôes inconscientes tenham um lugar de destaque é uma postura bem diferente daquela que se utiliza do saber $p s i$ para rotular os adolescentes, associando transtorno mental e criminalidade pela via da periculosidade, e ainda dos transtornos de personalidade antissocial, tomando o adolescente como intratável e irrecuperável, excluindo qualquer movimento de construção de planos socioeducativos e de intervenção (Rosa \& Vicentin, 2010) que possibilitem ao adolescente novas formas de vida.

O analista ou o psicólogo orientado pela psicanálise, em seu consultório ou não, é orientado pela ética de fazer existir o sujeito do inconsciente. No que concerne ao adolescente infrator, deverá fazer com que o adolescente se questione a respeito de seu ato, convocando-o a ser protagonista de sua história (Souza $\&$ Moreira, 2014), como um ser desejante.

Nesse sentido, há de se perguntar: quais efeitos o ato infracional suscita no psiquismo desse sujeito? Logo, a escuta analítica deverá oferecer ao sujeito possibilidade de responsabilização pelo ato, de reinserção sociofamiliar, de construção de um novo projeto de vida e de novos laços (Souza \& Moreira, 2014). O sujeito deverá aprender que "a cura não se sustenta a partir de uma resolução sintomática” (Guerra et al., 2014, p. 173), ou seja, utilizar-se de um sintoma para se curar do outro não lhe garantirá êxito em sua trajetória de vida. 
$\mathrm{O}$ ato infracional também pode ser relacionado à categoria de laço social. No ato, há algo de singular do gozo de cada um, pois há satisfação pulsional nos atos humanos, sejam eles impulsos amorosos e, ou, destrutivos (Guerra et al., 2014. p. 176). De outro modo, pode-se dizer que "A palavra tem sido deixada de lado, propiciando cada vez mais o reinado do gozo, em que se atestam modos inéditos de laço com o Outro, com predominância de sintomas onde a atuação substitui a enunciação" (Capanema \& Vorcaro, 2012, p. 156). Há de se trabalhar para que cesse de algum modo o gozo, por vezes mortífero para o sujeito e os seus semelhantes.

O encontro analítico existe visando a dar novo sentido ao adolescente, viabilizando alternativas saudáveis nas esferas da vida (Ayub \& Macedo, 2011). O trabalho que é feito é de abrir espaço para a fala, acolher o que é dito pelo sujeito, possibilitando que este construa possibilidades de autonomia e de inserção social por vias diferentes da criminalidade (Ferreira \& Vescovi, 2014). Dizendo de outro modo, que o sujeito se aproprie de seu sintoma e de seu malestar (Sena \& Farias, 2010). Ainda que continue a fazer as mesmas escolhas que antes, o sujeito deverá estar advertido de que essa decisão não lhe será sem consequências, perante as quais terá de responder.

Pela escuta analítica, espera-se que o sujeito possa se retificar subjetivamente. Significa que "a retificação pode ser considerada, portanto, como subjetiva, pois conduz o paciente a mudar a sua posição de sujeito frente aos modos permanentes pelos quais ele constitui os seus objetos" (Couto, 2004, apud Souza \& Moreira, 2014). Também que ele aperceba marcado pela incompletude, pelos limites e finitude humana; pela falta e pelo desejo que o movimentam psiquicamente (Ayub \& Macedo, 2011).

As instituições que acolhem jovens e adolescentes em conflito com a lei para cumprirem medidas socioeducativas têm seus ideais compreendidos como reeducação social, inclusão na sociedade, fortalecimento dos vínculos familiares, profissionalização, entre outros. Sabe-se que

Estes, no entanto, não podem esmagar o sujeito; deve haver espaço para a singularidade. O que vemos, porém, é que os ideais institucionais de reeducação, disciplinamento e adestramento do adolescente aniquilam qualquer possibilidade de manifestação de desejo e de reconhecimento desse sujeito (Rosário, 2010, p. 74).

É sobre essa realidade que se deve operar e buscar, nas brechas de um discurso totalitário, o sujeito e sua evanescência, seus pontos de captura e as migalhas que vão caindo na tessitura do seu discurso. 


\section{CONSIDERAÇÕES FINAIS}

Este estudo permitiu pensar que o ato infracional ocupa um lugar na dinâmica psíquica do sujeito, muitas vezes relacionada ao processo de adolescer, sua conflitiva edípica e presença ou não das figuras parentais, compreendidos como aqueles que desempenhem as funções paternas e maternas. Contudo outros elementos devem ser considerados, como falta de escolaridade, falta de acesso aos bens e à cultura, busca por notoriedade, inserção numa rede local, entre outros tantos fatores, denunciando questôes do sujeito, da família, da escola, da sociedade e do Estado. Logo, não há uma causa única e nem sempre se pode pensar em relação de causa e efeito.

Neste dado momento histórico, de mudanças históricas, sociais e econômicas que contribuem para a manutenção de fenômenos como a presença maciça de adolescentes envolvidos em atos infracionais, percebe-se uma queda dos referenciais familiares, da fragilização das funções parentais (Rodrigues, Mualem, Tostes, \& Teixeira, 2015) e horizontalização das relações familiares. Há a ilusão de que tudo pode e de não lidar com a falta, com a lei e com a interdição, como já nos alertava Roudinesco (2003) sobre as vicissitudes desse modelo familiar como uma "rede assexuada, fraterna, sem hierarquia nem autoridade, na qual cada um se sente autônomo ou funcionalizado" (p. 155). Escutar o adolescente envolvido em atos infracionais é acolher essa dinâmica que o atravessa, ao mesmo tempo em que possibilita a construção de saídas diante disso, sabendo que a castração, a falta é para todos, por ser constitutiva do sujeito e da qual não há como desviar. Ela é inexorável.

É relevante considerar que a adolescência é uma fase peculiar que carrega consigo as crises psíquicas. Mas não nos iludamos. Todas as pessoas, em diferentes etapas da vida, estão em crise, de alguma forma. O encontro com o real, o desemparo, a finitude e a impossibilidade se dão ao longo de toda a existência. E assim, a dor psíquica tem a importância de fazer o sujeito se locomover em direção ao outro, a construir novos projetos de vida e criar novos arranjos pelos quais a vida possa ser mais valorizada e útil.

Alguns adolescentes que hoje estão nas políticas especiais já se ingressaram nas políticas assistenciais em etapas anteriores de sua vida. Isso leva a pensar que a inclusão fracassa por ter um sentido universal da política, uma forma de controle e que vem do outro, diferentemente da inserção que diz da perspectiva do sujeito, de cada um, que é fundamental no ser falante (Salum, 2011; Miller, 2008 apud Salum \& Santiago, 2012). E é aqui que a psicanálise poderá, pela escuta clínica, marcar seu lugar de diferença ante as políticas públicas de assistência social, ou seja, para além da inclusão do indivíduo nas instituições que estão a serviço 
do Estado ou de outras formas de poder e de saber exercendo sobre ele algum controle, esse aporte teórico-clínico visa a favorecer ao sujeito a sua inserção, sendo esta entendida como uma relação que se estabelece pelos meios possíveis de negociação que o sujeito busca estabelecer com o Outro, fruto de sua mudança subjetiva (Teixeira, 2007).

A estruturação no acompanhamento das medidas socioeducativas é lenta e encontra dificuldades de toda maneira, desde a estrutura física e localização das unidades, a rotatividade da equipe técnica, a falta de profissionais que atenda às demandas, e ainda, o engessamento que a equipe encontra em aspectos burocráticos. Faz-se necessário que seja efetivado o PIA e o acompanhamento sistemático do adolescente, para que o tempo da medida seja mais bem aproveitado e possa marcar significativamente sua vida. Pois, como sabemos, o PIA, além de contar com a participação direta do adolescente, resguarda as especificidades de cada um deles, especialmente pela condição peculiar de desenvolvimento dos jovens, promove para estes a individualização da medida, por possibilitar a construção de um projeto mediante o qual o adolescente possa se posicionar diante de sua própria história e delinear expectativas para o seu futuro. Assim, "deve ser um instrumento que singularize o adolescente e contribua para a construção de uma subjetividade expressiva e criativa" (Moreira, Albuquerque, Rocha, Rocha, \& Vasconcelos, 2015, p. 345)

A clínica psicanalítica nas instituições de acolhimento a adolescentes e jovens que cometeram ato infracional resguarda para si o lugar privilegiado da fala e da escuta. Pois, como bem se sabe, o ato de falar poderá revelar algo que está além daquilo que se diz. As intervenções do psicanalista possibilitarão ao sujeito se confrontar com o seu desejo e deverá guardar a máxima lacaniana de que a psicanálise deve conduzir o tratamento e jamais a vida do sujeito.

Acredita-se, também, que, pela palavra, o sujeito poderá ressignificar o ato infracional e construir para si alternativas, outro projeto de vida, outra forma de reconhecimento, diferente do caminho que envolve a criminalidade, a infração e o delito. Assim, isso o tiraria da posição de vítima da própria sorte ou de um culpado que precisa pagar pelo crime cometido, sem reduzi-lo a determinações sociais, nomenclaturas e estigmatizações crescentes. Essa é uma das contribuiçôes da psicanálise, no sentido de possibilitar ao sujeito que viva mais esclarecido sobre as consequências de suas escolhas, que, inclusive afeta todo o ciclo de relações que ele estabelece com a família, os amigos, a escola e a comunidade.

Com base nos estudos analisados e discutidos sobre as questôes dos adolescentes, sua família, o ato infracional cometido e o fazer da clínica psicanalítica nesse campo, permite-se pensar que o trabalho que se faz é o de construção de uma 
subjetividade que abarca o inconsciente, a pulsão, o desamparo, a alteridade e a responsabilidade, considerando a lei simbólica e o lugar do Outro, considerando "que uma forma de vida se constitui por aquilo que ela perde e se constrói, pelo que ela retém. Uma forma de vida inclui um modo de subjetivação, uma gramática de desejo e uma forma específica de construção de fantasias" (Dunker, 2011, p. 22)

A contribuição que a psicanálise pode oferecer nesses espaços institucionais, em relação ao direito e à assistência social, é a escuta, que poderá funcionar como possibilidade de regulação social e de responsabilização subjetiva para os sujeitos, especialmente quando se se dá a efetivação da lei simbólica, a construção de um lugar de onde se leve em questão as particularidades de um sujeito adolescente e suas nuances inconscientes para além dos direitos adquiridos pela lei. 


\section{REFERÊNCIAS}

Altoé, S., \& Silva, M. M. (2013). Características de uma clínica psicanalítica com crianças e adolescentes em situação de vulnerabilidade social. Estilos da Clinica, 18(1), 125-141.

Amaro, J. W. F. (2004). O debate sobre a maioridade penal. Archives of Clinical Psychiatry, 31(3), 142-144.

Ayub, R. C. P., \& Macedo, M. M. K (2011). A clínica psicanalítica com adolescentes: especificidades de um encontro analítico. Psicologia: Ciência e Profissão, 31(3), 582-601.

Benhaim, M. (2011). Atuaçôes delinquentes, passagem ao ato suicida na adolescência. Ágora: Estudos em Teoria Psicanalítica, 14(2), 197-207. Recuperado a partir de https://www.scielo.br/scielo.php?script=sci_ arttext\&pid=S1516-14982011000200003

Brasil. (2013). Presidência da República. Secretaria de Direitos Humanos. Plano Nacional de Atendimento Socioeducativo: diretrizes e eixos operativos para o Sinase. Brasília: Secretaria de Direitos Humanos.

Brasil. (2015). Presidência da República. Secretaria de Direitos Humanos. Levantamento anual Sinase 2013. Brasília: Secretaria de Direitos Humanos.

Broide, J. (2010). Adolescência e violência: criação de dispositivos clínicos no território conflagrado das periferias. Psicologia Política, 10(19), 95-106.

Capanema, C. A., \& Vorcaro, A. (2012). Modalidades do ato na particularidade da adolescência. Ágora: Estudos em Teoria Psicanalítica, 15(1), 151-163.

Cardoso, F. M. (2014). A língua dos anjos: um estudo sobre a criança em face da lei e da psicanálise em margem a redução da maior idade penal. Revista Juris Rationis, 7(2), 119-127.

Costa, A. B., \& Zolowski, A. P. C. (2014). Como escrever um artigo de revisão sistemática. In S. H. Koller, M. C. P. P. Couto, \& J. Von Hohendorff (Eds.), Manual de produção cientifica. (pp. 55-70). Porto Alegre: Penso.

Costa, L. F., Penso, M. A., Sudbrack, M. F. O., \& Jacobina, O. M. P. (2011, julhosetembro). Adolescente em conflito com a lei: o relatório psicossocial como ferramenta para a promoção do desenvolvimento. Psicologia em Estudo, 16(3), 
379-387. Recuperado a partir de https://www.scielo.br/scielo.php?script=sci_ arttext\&pid=S1413-73722011000300005

Crianças e jovens da América Latina à mercê do crime organizado. (2016, 27 maio). Istoé. Recuperado a partir de https://istoe.com.br/criancas-e-jovens-daamerica-latina-a-merce-do-crime-organizado-cidh/

Danziato, L. J., Carvalho, M. P., \& Paiva, H. S. (2013). A adolescência e o deslocamento do campo discursivo: impasses e implicações para os processos de subjetivação contemporâneos. Trivium: Estudos Interdisciplinares, 5(2), 7682. Recuperado a partir de http://pepsic.bvsalud.org/scielo.php?script=sci_ arttext\&pid=S2176-48912013000200011

Dunker, C. I. L. (2011). Crítica da razão diagnóstica: mal-estar, sofrimento e sintoma na experiência psicanalitica brasileira. São Paulo: Universidade de São Paulo. mimeo.

Fernández-Ríos, L., \& Buela-Casal, G. (2009). Standards for the preparation and writing of Psychology review articles. International Journal of Clinical and Health Psychology, 9, 329-344.

Ferrari, I. F. (2006). Agressividade e violência. Psicologia Clínica, 18(2), 49-62.

Ferreira, V. V. F., \& Vescovi, R. G. L. (2013). Na impossibilidade da palavra, ao ato: adolescência e a lei. Pesquisas e Práticas Psicossociais, 8(2), 207-215.

Gregoracci, L. M., \& Onofre, E. M. C. (2013). O programa de medidas socioeducativas em meio aberto: vozes dos adolescentes em conflito com a lei. Revista do Laboratório de Estudos da Violência e Segurança, 12, 87-99. Recuperado a partir de https://doi.org/10.36311/1983-2192.2013.v0n12.3478

Guerra, A. M. C., \& Cunha, C. F. (2015). Agressividade e violência: formas de penar o humano e o inumano. In A. M. C. Guerra, C. F. Cunha, \& R. S. Silva. (Orgs.). Violência, território, família e adolescência: contribuiçôes para a Política de Assistência Social. Belo Horizonte: Scriptum.

Guerra, A. M. C., Cunha, C. F., Costa, M. H., \& Silva, T. L. (2014). Risco e sinthome: a psicanálise no sistema socioeducativo. Psicologia: Teoria e Pesquisa, 30(2), 171-177.

Lacadée, P. (2012). A clínica da língua e do ato nos adolescentes. Responsabilidades, 1(2), 253-268. 
Lacan, J. (1964/2008). Seminário 11: os quatro conceitos fundamentais da psicanálise. Rio de Janeiro: Jorge Zahar, 2008. (Publicado originalmente em 1964).

Lei no 8.069, de 13 de julho de 1990 (1990, 13 julho). Dispõe sobre o Estatuto da Criança e do Adolescente e dá outras providências. Diário Oficial da União, Brasília. Recuperado a partir de http://www.planalto.gov.br/ccivil_03/Leis/ L8069.htm

Marin, I. S. K. (2009). A clínica institucional da adolescência (entre o aborrecente e o herói: quem é o adolescente na escuta psicanalítica?). Revista Brasileira de Adolescência e Conflitualidade, 1(1).

Marino, A. S., \& Priszkulnik, L. (2011). Nome do Pai e o discurso do capitalista contribuiçôes psicanalíticas a uma clínica com jovens autores de ato infracional. Revista Brasileira de Adolescência e Conflitualidade, 4, 68-80.

Melgaço, P., Moreira, J. O., Araújo, E. C. M., Vasconcelos, M. A. M., Tavares, P. R., \& Pompeu, M. (2014). Da atuação de psicólogos orientados pela psicanálise à relação transferencial nas medidas socioeducativas: considerações para uma prática. Analytica: Revista de Psicanálise, 3(5), 115136. Recuperado a partir de http://pepsic.bvsalud.org/scielo.php?script=sci_ arttext\&pid=S2316-51972014000200007

Mohr, A. M., \& Valore, L. A (2009). Rebeldia adolescente: um olhar à luz das contribuições da psicanálise. Psicodom, 1(4), 1-18.

Moreira, J. O., Albuquerque, B. S., Rocha, B. F., Rocha, P. M, \& Vasconcelos, M. A. M. (2015). Plano individual de atendimento na perspectiva dos técnicos da semiliberdade. Serviço Social \& Sociedade, 122, 341-356. Recuperado de https://dx.doi.org/10.1590/0101-6628.026

Muller, F., Barboza, P. S., Oliveira, C. C., Santos, R. R. G., Paludo, S. S. (2009). Perspectivas de adolescentes em conflito com a lei sobre o delito, a medida de internação e as expectativas futuras. Revista Brasileira de Adolescência e Conflitualidade, 1(1), 70-87.

Organização dos Estados Americanos. (2015). Comisión Interamericana de Derechos Humanos. Violencia, niñez y crimen organizado. Washington: CIDH. Recuperado a partir de http://www.oas.org/es/cidh/informes/pdfs/ ViolenciaNinez2016.pdf

Padovani, A. S., \& Ristum, M. (2013). A escola como caminho socioeducativo 
para adolescentes privados de liberdade. Educação e Pesquisa, 39(4), 969984, Recuperado a partir de https://www.scielo.br/scielo.php?script=sci_ arttext\&pid=S1517-97022013000400010\&lng=pt\&tlng=pt

Rassial, J. J. (1997). A passagem adolescente: da família ao laço social. Porto Alegre: Artes e Ofícios.

Rassial, J. J. (1999). O adolescente e o psicanalista. Rio de Janeiro: Cia. de Freud.

Rodrigues, S. W. D. M., \& Teixeira, L. (2014). Sobre a adolescência e o ato infracional: pontuações psicanalíticas. In J. O. Moreira, A. M. C. Guerra, \& J. M. P. Sousa. (Orgs.), Diálogos com o campo das medidas socioeducativas: conversando com a semiliberdade e a internação. Curitiba: CRV.

Rodrigues, S. W. D., Mualem, W., Tostes, T., Teixeira, L. C. (2015). O adolescente, a família e a instituição: vicissitudes da posição diante da lei e do ato infracional. In J. O. Moreira, J. M. P. Souza, \& P. M. Rocha, (Orgs.). Diálogos com o campo das medidas socioeducativas: conversando sobre a acolhida, os eixos e o desligamento. (pp. 130-140). Curitiba: CRV.

Rosa, M. D., \& Vicentin, M. C (2010). Os intratáveis: o exílio do adolescente do laço social pelas noções de periculosidade e irrecuperalidade. Revista Psicologia Politica, 10(19), 107-124.

Rosário, A. B. (2010). Grupo de adolescentes em privação de liberdade: circulação da palavra como possibilidade de ressignificação do ato infracional. Revista da Sociedade de Psicoterapias Analíticas Grupais do Estado de São Paulo (SPAGESP), 11(1), 66-76.

Roudinesco, E. (2003). A família em desordem. Rio de Janeiro: Zahar.

Salum, M. J. G. (2011, novembro). O grupo como estratégia de (des)inserção em adolescentes institucionalizados. Revista aSEPHallus, 6(11). Recuperado a partir de http://www.isepol.com/asephallus/numero_11/artigo_07_revista11. html

Salum, M. J. G., \& Santiago, A. L. (2012, maio-outubro). Os adolescentes desinseridos e seus sintomas nas instituições socioeducativas. Revista aSEPHallus, 7(14). Recuperado a partir de http://www.isepol.com/asephallus/ numero_14/artigo_08.html

Santos, M. A., \& Pratta, E. M. M. (2012). Adolescência e o uso de drogas à luz da psicanálise: sofrimento e êxtase na passagem. Tempo Psicanalítico, 44(1), 
$167-182$.

Santos, T. C., \& Zeitoune, C. M. (2011). Amor, impasses da sexuação e ato infracional na adolescência. Tempo Psicanalitico, 43(1), 85-108.

Sena, I. J., \& Farias M. L. S. O. (2010). Função paterna e adolescência e suas relaçôes com a violência escolar. Revista Mal-Estar e Subjetividade, 10(1), 111136.

Silva, R. A., \& Araújo, S. M. B. (2013). A representação da função paterna para as instituições de auxílio a adolescentes em conflito com a lei. Psicologia Clínica, 25(1), 37-52.

Souza, J. M. P., \& Moreira, J. O. (2014). Psicanálise e Direito: escutar o sujeito no âmbito das medidas socioeducativas. Estudos e Pesquisas em Psicologia, 14(1), 182-200.

Teixeira, A. (2007). Da inserção em saúde mental. Revista aSEPHallus, 6(11). Recuperado a partir de http://www.isepol.com/asephallus/numero_11/ artigo_04_revista11.html

Teixeira, L. C. (2014). O sujeito adolescente e a intervenção psicanalítica: notas a partir de um caso clínico. Revista Latino-Americana de Psicopatolologia Fundamental, 17(3), supl. 1.

Vilhena, J., Zamora, M. H. R. N., \& Rosa, C. M. (2011). Da lei dos homens à lei da selva: sobre adolescentes em conflito com a lei. Trivium - Estudos Interdisciplinares, 3(2), 27-40. Recuperado a partir de http://pepsic.bvsalud. org/scielo.php?script=sci_arttext\&pid=S2176-48912011000200005\&lng=pt \&tlng=pt

Waiselfisz, J. J. (2014). Homicídios e juventude no Brasil. Brasília: Secretaria-Geral da Presidência da República. Secretaria Nacional de Juventude. Secretaria de Políticas de Promoção da Igualdade Racial.

Xavier, R. B. T., Ferreira, C. V. L, \& Paravidini, J. L. L. (2011). Adolescentes em conflito com a lei função materna e transmissão do nome do pai. Revista MalEstar e Subjetividade, 6(1), 41-56.

Zeitoune, C.M. (2009, maio-outubro).Ética, lei eresponsabilidade: considerações sobre o atendimento clínico em adolescentes. Revista aSEPHallus, 4(8), 4360. Recuperado a partir de http://www.isepol.com/asephallus/numero_08/ artigo_03_port.html 